\title{
Effects of Prolonged Night Shifts on Salivary $\alpha$-Amylase, Secretory Immunoglobulin, Cortisol, and Chromogranin A Levels in Nurses
}

\author{
Yosuke Morita1*, Hideko Aida², Takuji Yamaguchi' ${ }^{3}$, Masakazu Azuma1, Sennichi Suzuki, \\ Nobuhiro Suetake', Takehiko Yukishita', Keiko Lee ${ }^{3}$, Hiroyuki Kobayashi1,3 \\ ${ }^{1}$ Department of Hospital Administration, Juntendo University Graduate School of Medicine, Tokyo, Japan \\ 2Juntendo University Koshigaya Hospital, Saitama, Japan \\ ${ }^{3}$ Center for Advanced Kampo Medicine and Clinical Research, Juntendo University Graduate School of \\ Medicine, Tokyo, Japan \\ Email: *yomorita@juntendo.ac.jp
}

Received 12 June 2014; revised 29 July 2014; accepted 15 August 2014

Copyright (C) 2014 by authors and Scientific Research Publishing Inc.

This work is licensed under the Creative Commons Attribution International License (CC BY).

http://creativecommons.org/licenses/by/4.0/

cC) (i) Open Access

\section{Abstract}

Prolonged night shift is associated with high burnout rate, but the physiological effects of a $16 \mathrm{~h}$ shift remain undetermined. Here we evaluated fatigue and stress via salivary assays to determine the correlation between stress and fatigue and prolonged night shifts. Twenty-five nurses ( 9 men, 16 women; 16 h night shift $(n=13), 8 \mathrm{~h}$ day shift $(n=12)$ ) from Juntendo University Koshigaya Hospital were evaluated for four consecutive workdays separated by off days. Salivary samples were collected upon waking and before sleep on non-working days, before and after the day and night shifts, and before and after the break during the nocturnal schedule, and analyzed for levels of cortisol, chromogranin A, $\alpha$-amylase activity and secretory immunoglobulin A (sIgA). On nonworking days, cortisol levels showed similar kinetic pattern in both nurses. On working days, daytime nurses' cortisol levels showed normal circadian pattern throughout the shift. Night nurses' cortisol levels at the beginning of the shift were comparable to that of the normal morning elevation. $\alpha$-Amylase activity in the night shift nurses was higher than day shift nurses through each period. No significant differences in chromogranin A and SIgA levels were detected between day and night shift workers. A 16 h night shift may cause marked circadian misalignment in cortisol levels.

\section{Keywords}

Stress, Salivary Markers, Night Shift Work, Nurse

\footnotetext{
${ }^{*}$ Corresponding author.
}

How to cite this paper: Morita, Y., et al. (2014) Effects of Prolonged Night Shifts on Salivary $\alpha$-Amylase, Secretory Immunoglobulin, Cortisol, and Chromogranin A Levels in Nurses. Health, 6, 2014-2025. 


\section{Introduction}

Nurses provide care around the clock in a three-shift system (daytime $\rightarrow$ nighttime $\rightarrow$ late night) consisting of three $8 \mathrm{~h}$ shifts within 24 hours, or in a two-shift system with an $8 \mathrm{~h}$ day shift and a $16 \mathrm{~h}$ night shift. In contrast with the three-shift system, the benefit of the two-shift system is in ensuring the safety of nurses by having them leave work before midnight, as well as reassuring the patients by providing continuity of care by the same nursing staff. Nevertheless, the long $16 \mathrm{~h}$ shift is apt to cause physical and mental exhaustion and disrupt the normal circadian rhythm [1]. Furthermore, many reports have confirmed that prolonged night schedule is highly stressful [2] [3] and associated with higher burnout rates [4] [5] and medical errors, but the precise physiological effects of a $16 \mathrm{~h}$ shift remain undetermined. Most assessments of fatigue rely on questionnaires that evaluate subjective fatigue severity while practical, objective evaluations are virtually nonexistent. In this study, we collected salivary samples as a simple and minimally invasive method of biochemically evaluating fatigue and stress [6] [7]. The aim of this study was to objectively measure fatigue and stress via salivary assays and determine the correlation between stress and fatigue and prolonged night shifts in order to generate data that would be informative for improving the work hours and well-being of nurses.

\section{Participants and Methods}

\subsection{Participants}

This study was approved by the Ethics Committee of Juntendo Uninversity. Participants included 25 nurses (9 men, 16 women; 13 nurses on a 16 h night shift, 12 on an 8 h day shift) from Juntendo University Koshigaya Hospital.

For the study, the $16 \mathrm{~h}$ nocturnal shifts were worked in 4 day stretches, with no more than a day off before and after the consecutive workdays. The $8 \mathrm{~h}$ daytime shifts were also worked in 4 day stretches, with no more than a day off before and after the consecutive workdays (see Scheme 1).

\subsection{Salivary Sampling}

Among the night workers, salivary samples were collected on a non-working day upon waking and before bedtime (day 1, before the 4 day consecutive shift), on workdays at the start of shift, start of break, after the break, and at end of the shift (days 2-5), and throughout the day until bedtime on the final non-working day (day 6). Among daytime nurses, samples were collected on a non-working day upon waking and before bedtime (day 1, before the 4 day consecutive shift), on workdays before and after the shift (days 2-5), and throughout the day until bedtime on the final non-working day (day 6). Saliva samples were collected using the tasteless and odorless

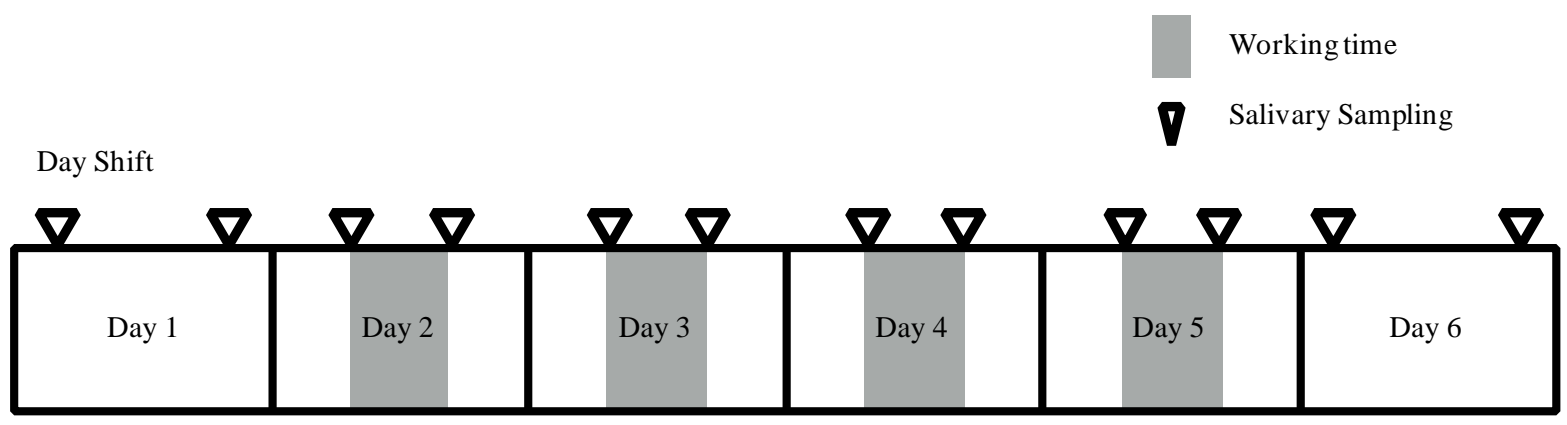

Night Shift

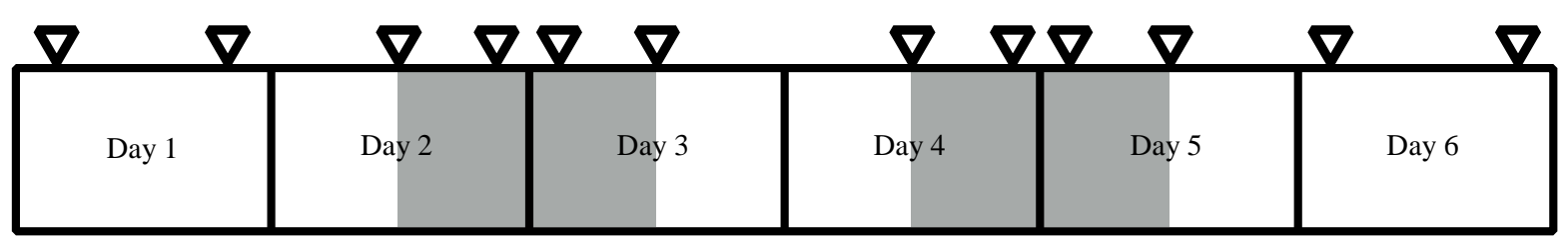

Scheme 1. Nurses' shift pattern and time points for saliva collection. 
oral swabs (Salimetrics, USA) retained in the mouth for $5 \mathrm{~min}$ in a seated position, and the collected saliva was centrifuged at $1500 \mathrm{rpm}$ for $40 \mathrm{~min}$ at $4^{\circ} \mathrm{C}$. The collected saliva was stored by the freezing.

\subsection{Measurements of Salivary Components}

Measured salivary components included cortisol, chromogranin A, $\alpha$-amylase activity and secretory immunoglobulin A (sIgA) levels. Comparative analysis was performed for the measured parameters obtained in the evening on days 2 and 4 and in the morning on days 3 and 5 between day and night shift nurses (see Scheme 2).

Cortisol levels were measured with the Salivary Cortisol Enzyme Immunosassay Kit (Salimetrics, USA), and chromogranin A levels with the Human Chromogranin A EIA Kits (Yanihara Institute Inc, Shizuoka, Japan). The Salivary $\alpha$-Amylase Assay Kit (Salimetrics, USA) was used to determine the $\alpha$-amylase activity whose activity level was corrected for by using salivary protein concentrations, and comparisons were made between the two groups. Salivary protein concentrations were measured with the Pierce BCA Protein Assay Kit (Thermo Scientific, Rockford, USA). The sIgA levels were measured with the Salivary Secretory IgA Indirect Enzyme Immunoassay Kit (Salimetrics, USA). The levels of each component were compared between the two groups. Results are shown as mean \pm S.E.

\subsection{Statistical Analysis}

Wilcoxon rank sum test was used to compare the levels of salivary components between the day and night shift nurses. A $p$-value of less than 0.05 was considered statistical significant.

\section{Results}

Measurements of salivary components such as cortisol, chromogranin A, $\alpha$-amylase activity and sIgA levels were used to determine the implications of prolonged night shifts on physical health in nurses.

\subsection{Salivary Cortisol Levels}

Cortisol levels of day and night shift workers are shown in Figure 1 and Figure 2, respectively. A comparative analysis of these levels is shown in Figure 3.

Cortisol levels of both types of nurses peaked in the morning and declined at night on non-working days. Similar kinetic changes were observed among the day shift nurses on working days. In addition, cortisol levels appeared to increase over time during the shift among daytime nurses.

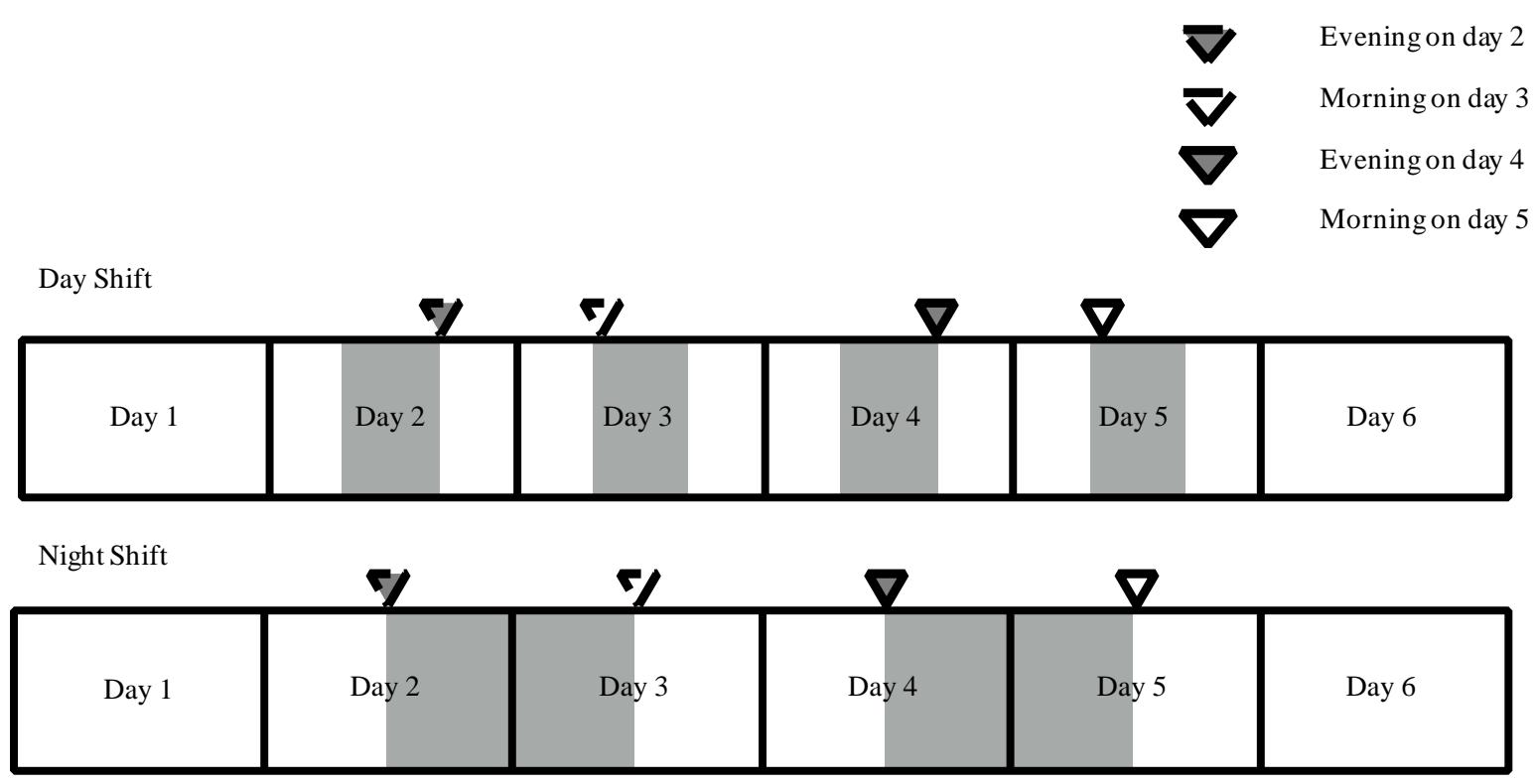

Scheme 2. Time points for comparative analysis of salivary markers between day and night shift nurses. 


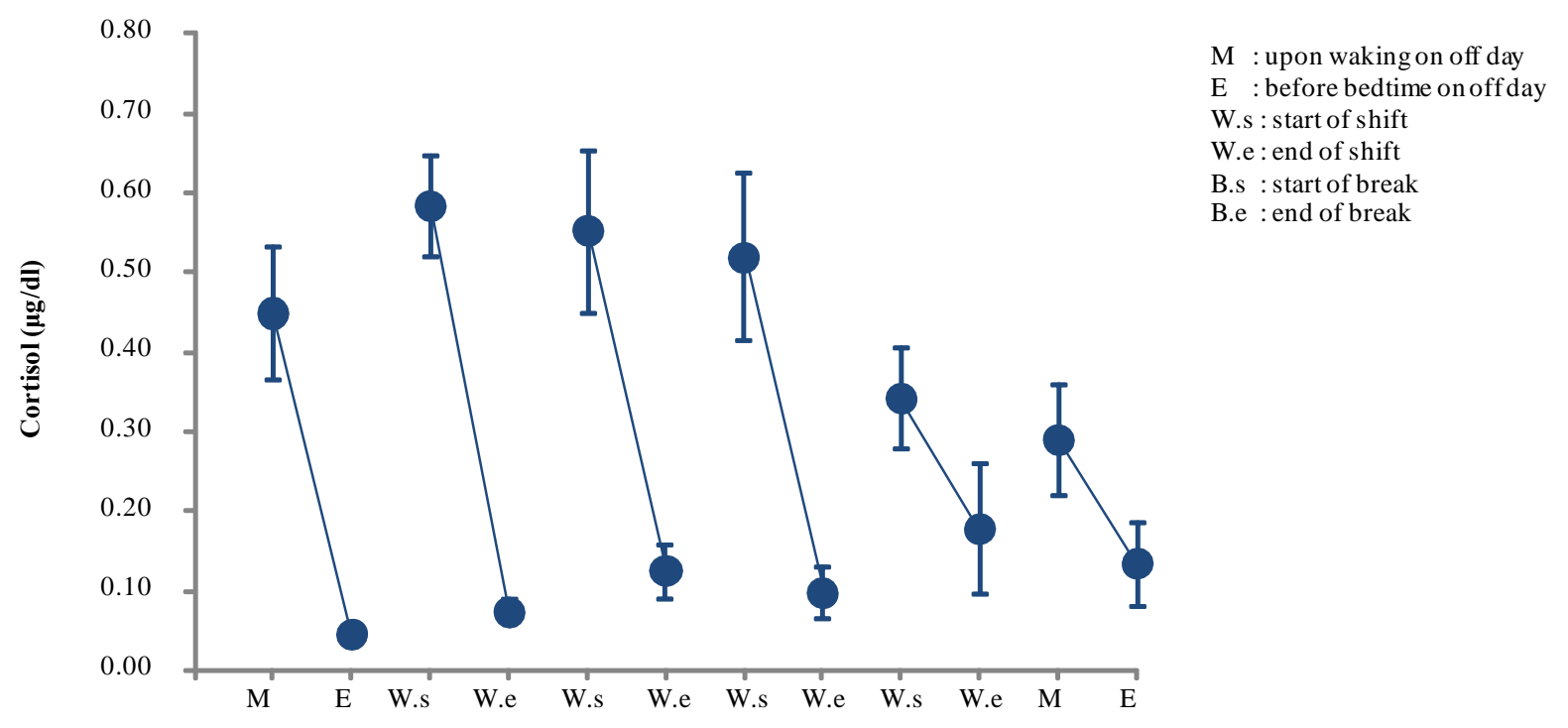

Figure 1. Changes in salivary cortisol levels of day shift work (mean \pm S.E.).

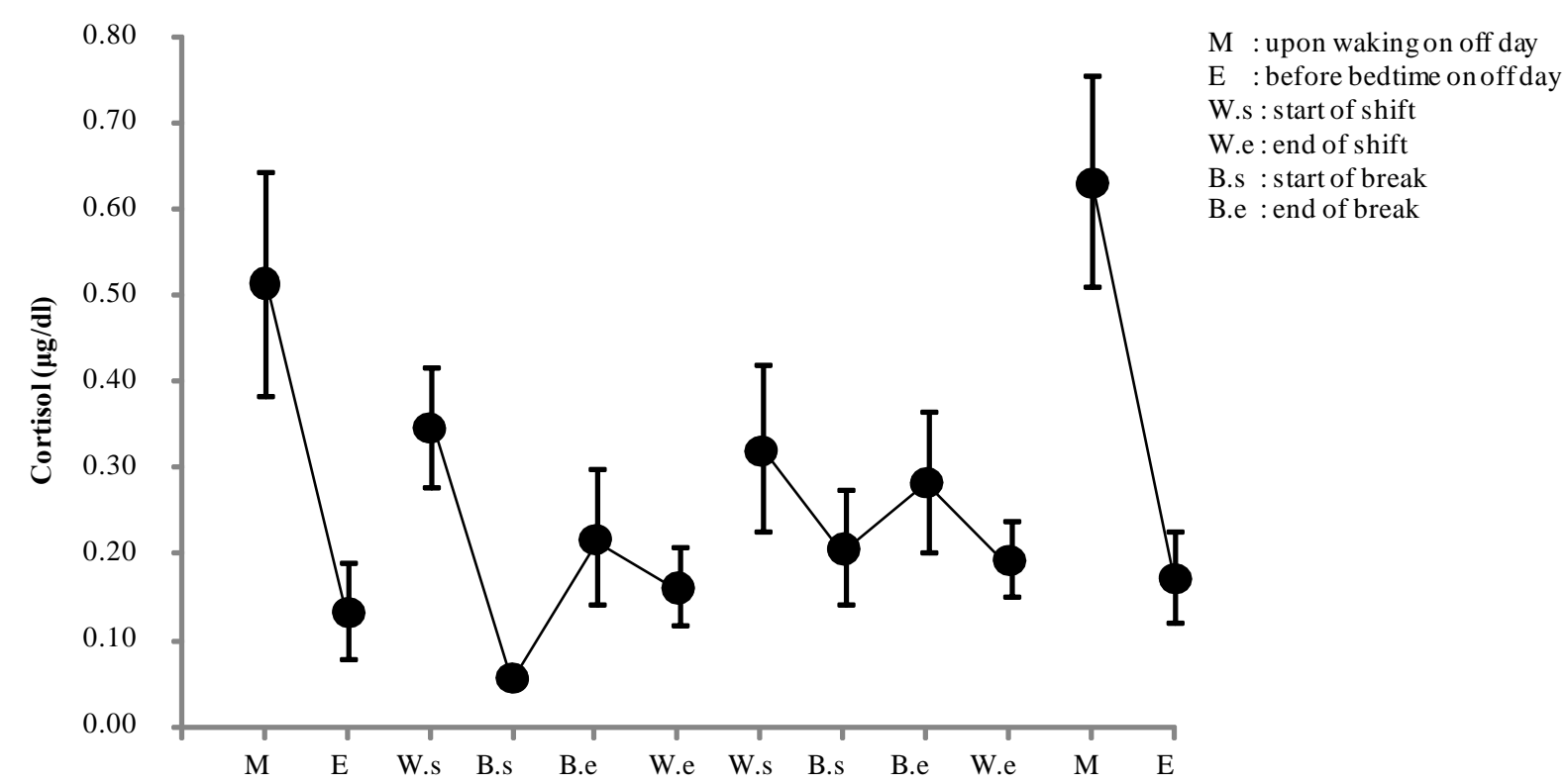

Figure 2. Changes in salivary cortisol levels of night shift work (mean \pm S.E.).

With respect to morning cortisol levels, the levels peaked on day 2 and declining steadily by day 6 . By contrast, lowest levels $(0.047 \pm 0.014 \mu \mathrm{g} / \mathrm{dl})$ occurred before bedtime on a non-working day (day 1), which gradually increased over the course of the study period by day 5 , only to decrease again before bedtime on a non-working day (day 6) (see Figure 1).

Among the nighttime nurses, despite the shift starting in the early evening, cortisol levels peaked before the shift, declined before the break, increased after the break, and decreased at the end of the shift (i.e., early morning). Interestingly, changes in cortisol levels on day 3 were minimal compared to those of day 2. Diurnal variations on off days revealed that the highest levels occurred on the morning of day $6(0.634 \pm 0.122 \mu \mathrm{g} / \mathrm{dl})$ (see Figure 2).

Cortisol levels in the evening of night shift nurses were significantly higher than those of the day shift nurses on day $2(p<0.001)$ and day $4(p<0.05)$. On the other hand, cortisol levels in the morning of night shift nurses were significantly lower than those of the day shift nurses on day $3(p<0.001)$. There were significant differences between day and night shift nurses (see Figure 3). 


\subsection{Salivary Chromogranin A Levels}

Chromogranin A levels of day and night shift nurses are shown in Figure 4 and Figure 5, respectively. A comparative analysis of these levels is shown in Figure 6.

Among the daytime nurses, chromogranin levels peaked at the end of day $5(0.01781 \pm 0.0109 \mathrm{pmol} / \mu \mathrm{g})$. The overall increase was driven by a significant increase in one of the nurses, as all other nurses did not show significant changes during the study period (see Figure 4). The one nurse with a significant increase in chromogranin A levels also had a similar and concurrent elevation in $\alpha$-amylase levels, prompting the need to identify the potential cause during the day shift that instigated the marked elevations.

Among the nighttime nurses, chromogranin A levels peaked in the morning and decreased at night on a non-working day (day 1). On day 2, the levels increased shortly before the break until the end of the shift. By contrast, on day 3 the levels increased from the start of shift until the break and declined after the break, but no other marked changes were observed until the end of the shift (see Figure 5).

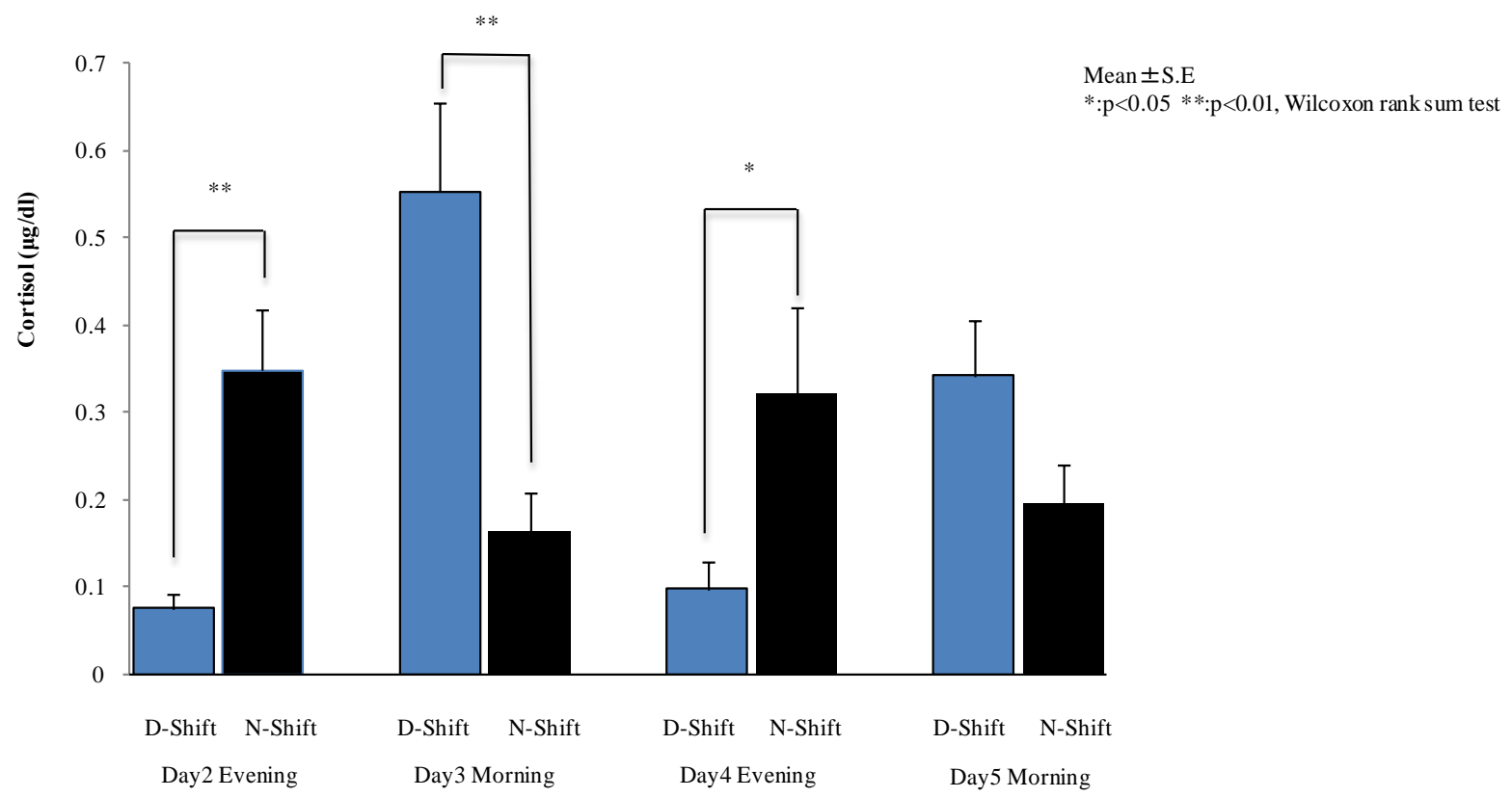

Figure 3. Comparative analysis between day and night shift nurses (Wilcoxon rank sum test).

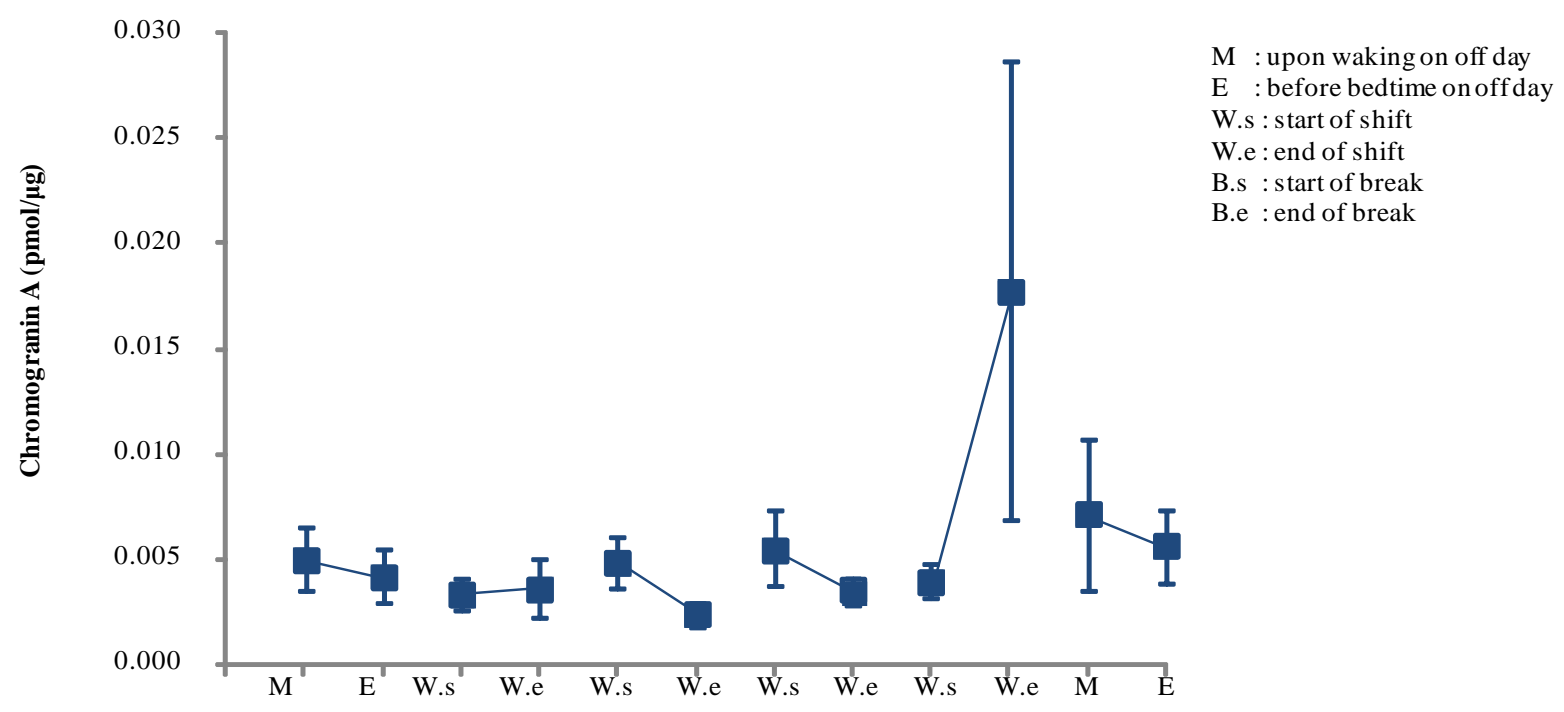

Figure 4. Changes in salivary chromogranin A levels of day shift work (mean \pm S.E.). 


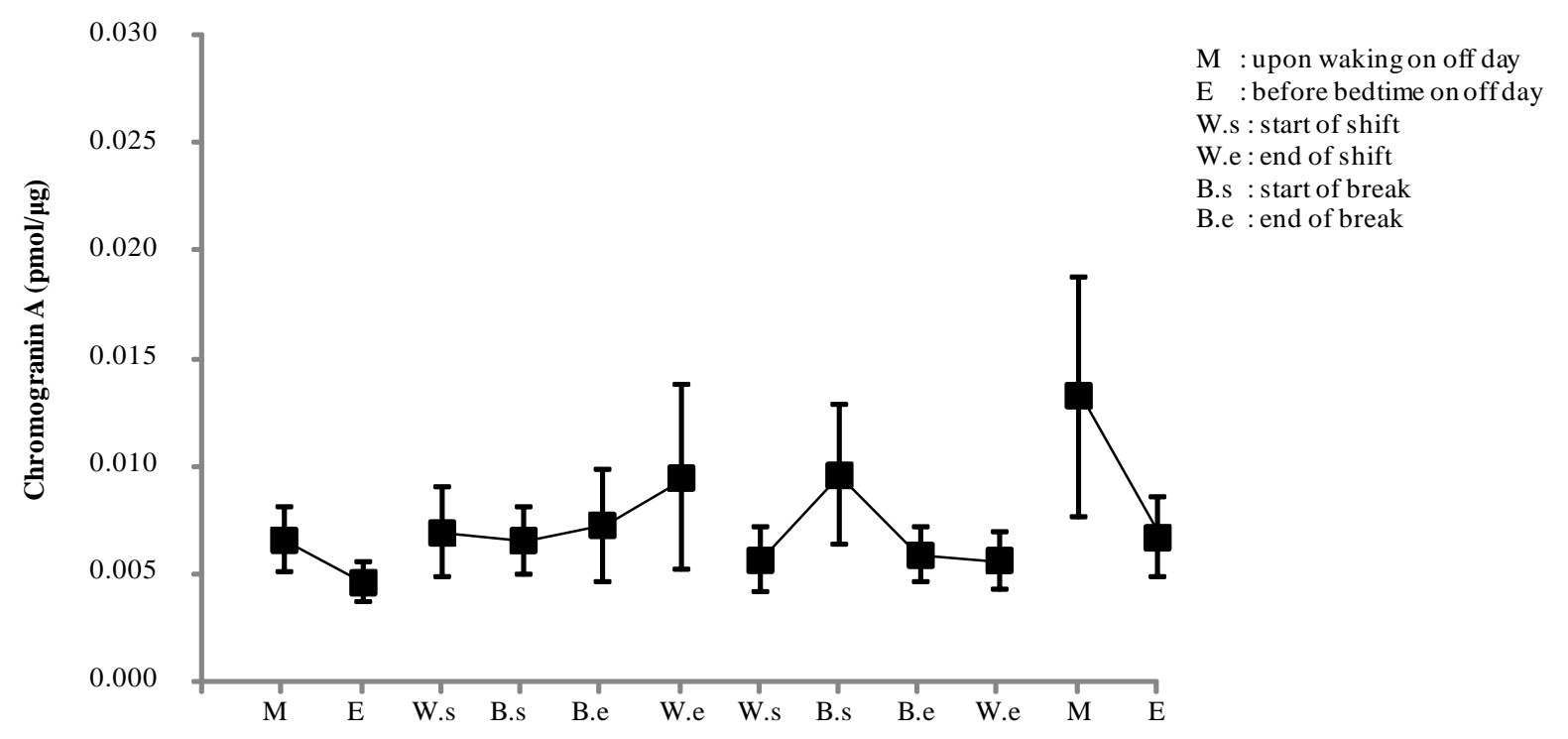

Figure 5. Changes in salivary chromogranin A levels of night shift work (mean \pm S.E.).

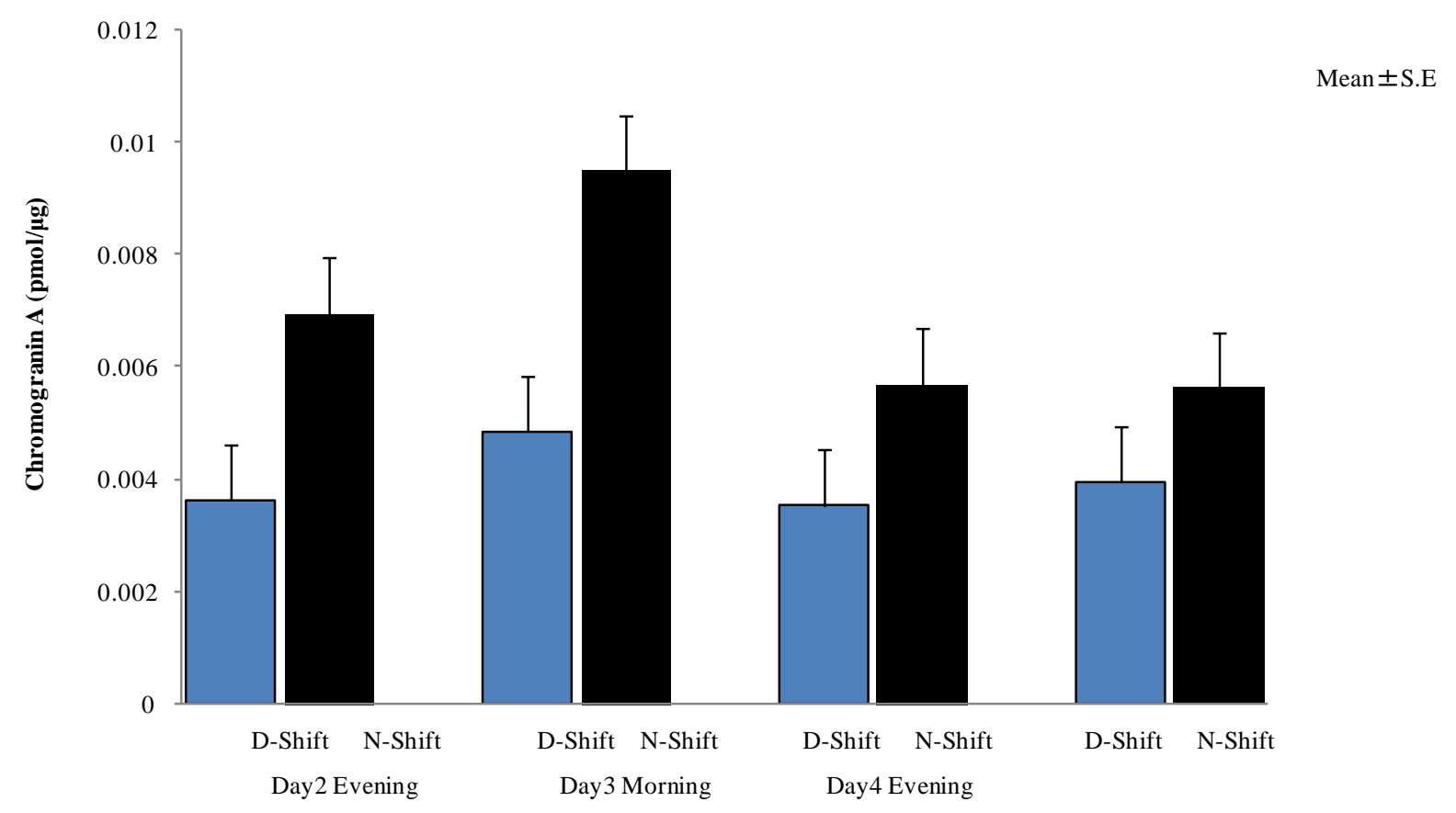

Figure 6. Comparative analysis between day and night shift nurses (Wilcoxon rank sum test).

There were no significant differences between day and night shift nurses (see Figure 6).

\subsection{Salivary $\alpha$-Amylase Activity}

$\alpha$-Amylase activity of day and night shift nurses are shown in Figure 7 and Figure 8, respectively. A comparative analysis of the activity is shown in Figure 9.

Among daytime nurses, the activity levels increased significantly before the off day (day 6 , end of the $4^{\text {th }}$ consecutive day shift), reaching a peak level of $0.343 \pm 0.287 \mathrm{U} / \mu \mathrm{g}$. However, this overall increase was driven by a significant increase observed in only one of the nurses, as all other nurses showed only a mild elevation at the end of their 4 day shift and without significant changes throughout the study period (see Figure 7). Thus, further investigation appears warranted to determine the cause for the significant increase in the one day shift worker. 


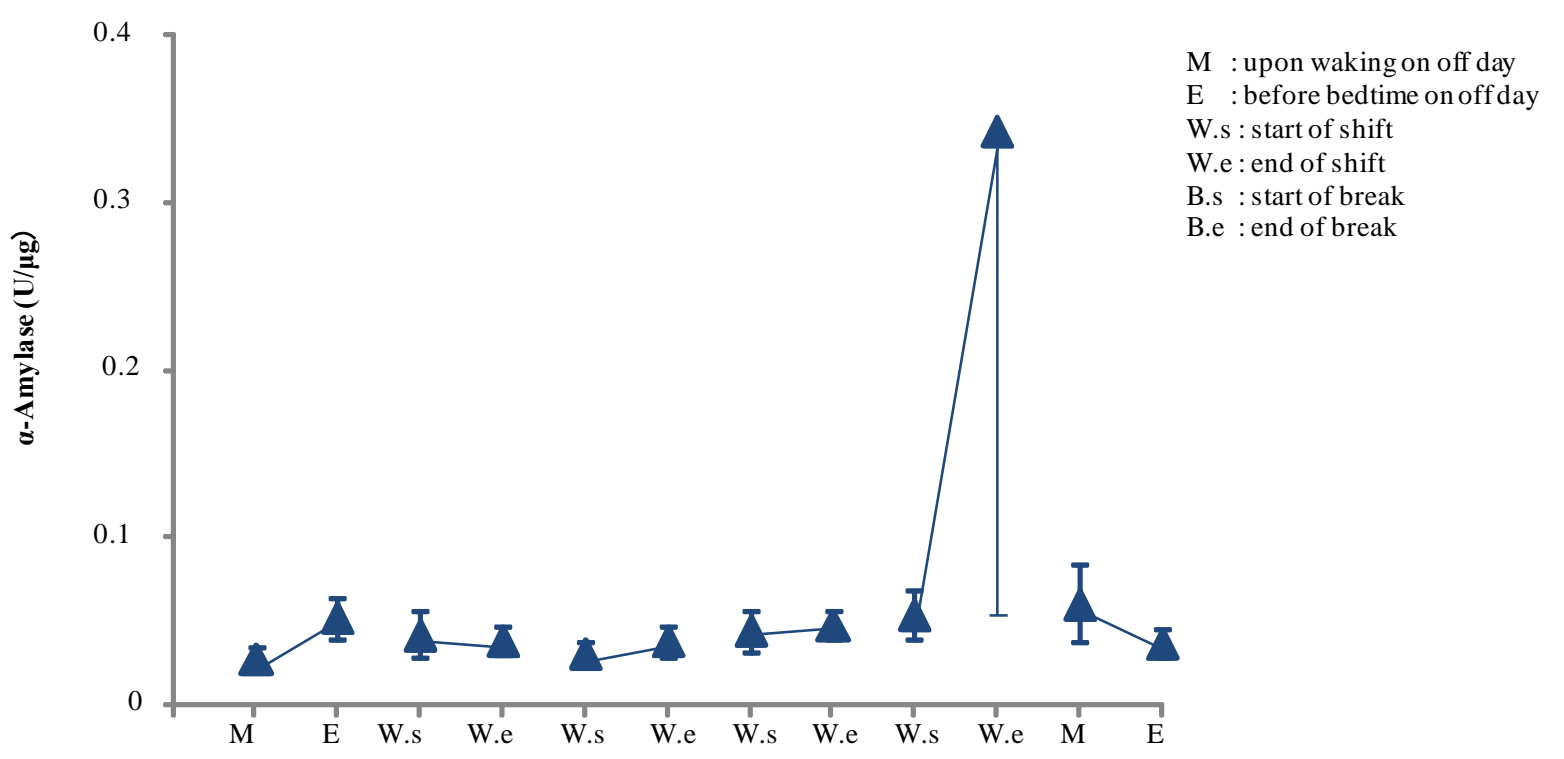

Figure 7. Changes in salivary $\alpha$-amylase activity of day shift work (mean \pm S.E.).

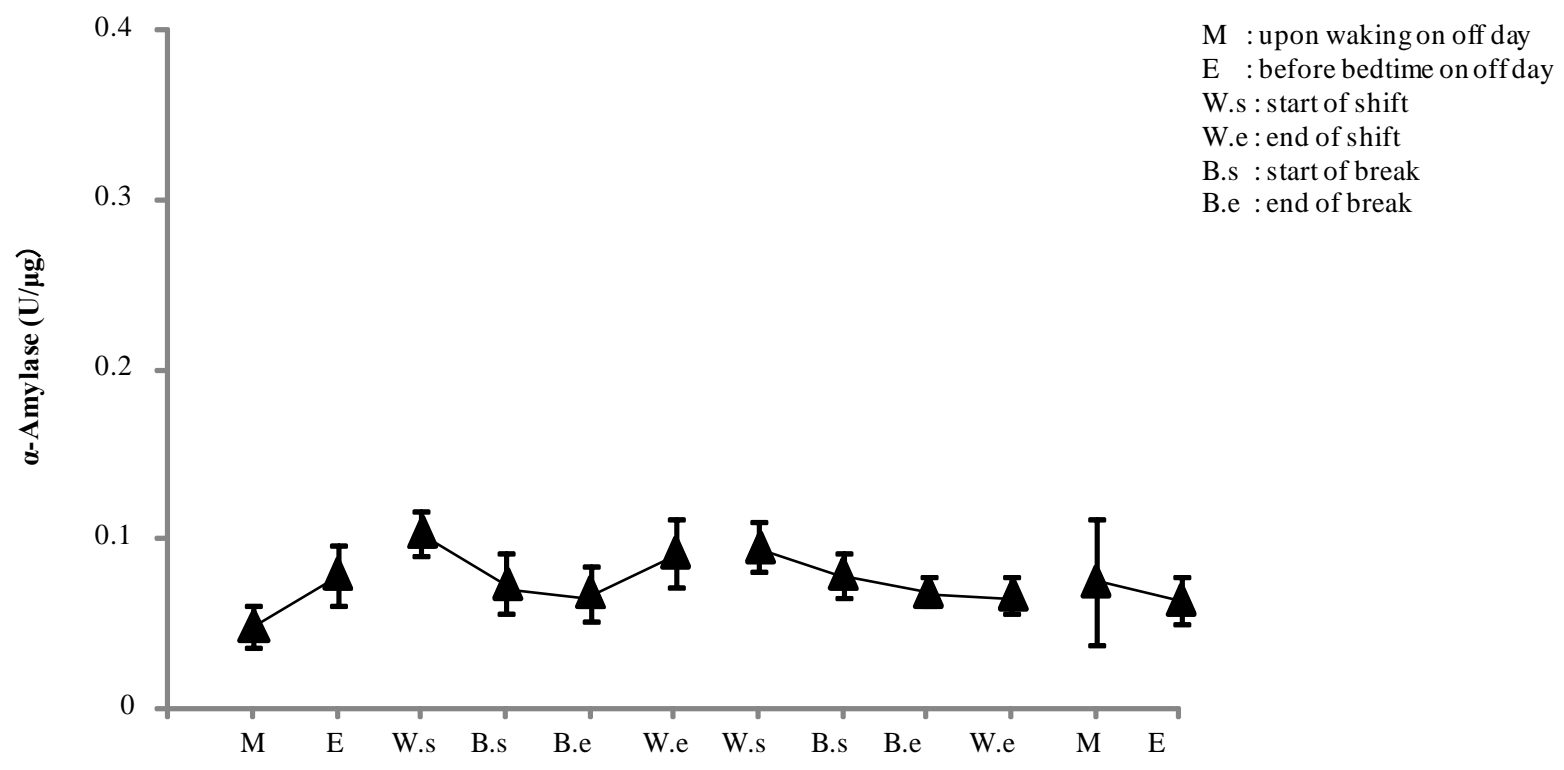

Figure 8 . Changes in salivary $\alpha$-amylase activity of night shift work (mean \pm S.E.).

By contrast, none of the nighttime nurses showed any significant changes in the $\alpha$-amylase activity (see Figure 8).

$\alpha$-Amylase activity in the evening of the night shift nurses was significantly higher than that in day shift nurses on day $2(p<0.001)$ and day $4(p<0.05)$. On the other hand, $\alpha$-amylase activity in the morning of night shift nurses was significantly higher than that of the day shift nurses on day $3(p<0.05)$. There were significant differences between day and night shift nurses (see Figure 9).

\subsection{Salivary sIgA Levels}

sIgA levels of day and night shift nurses are shown in Figure 10 and Figure 11, respectively. A comparative analysis of the levels is shown in Figure 12.

In this study, sIgA levels of the daytime nurses peaked on the morning of a non-working day (day 1) (105.301 $\pm 51.11 \mu \mathrm{g} / \mathrm{mL}$ ), but no other marked changes were observed thereafter (see Figure 10). 


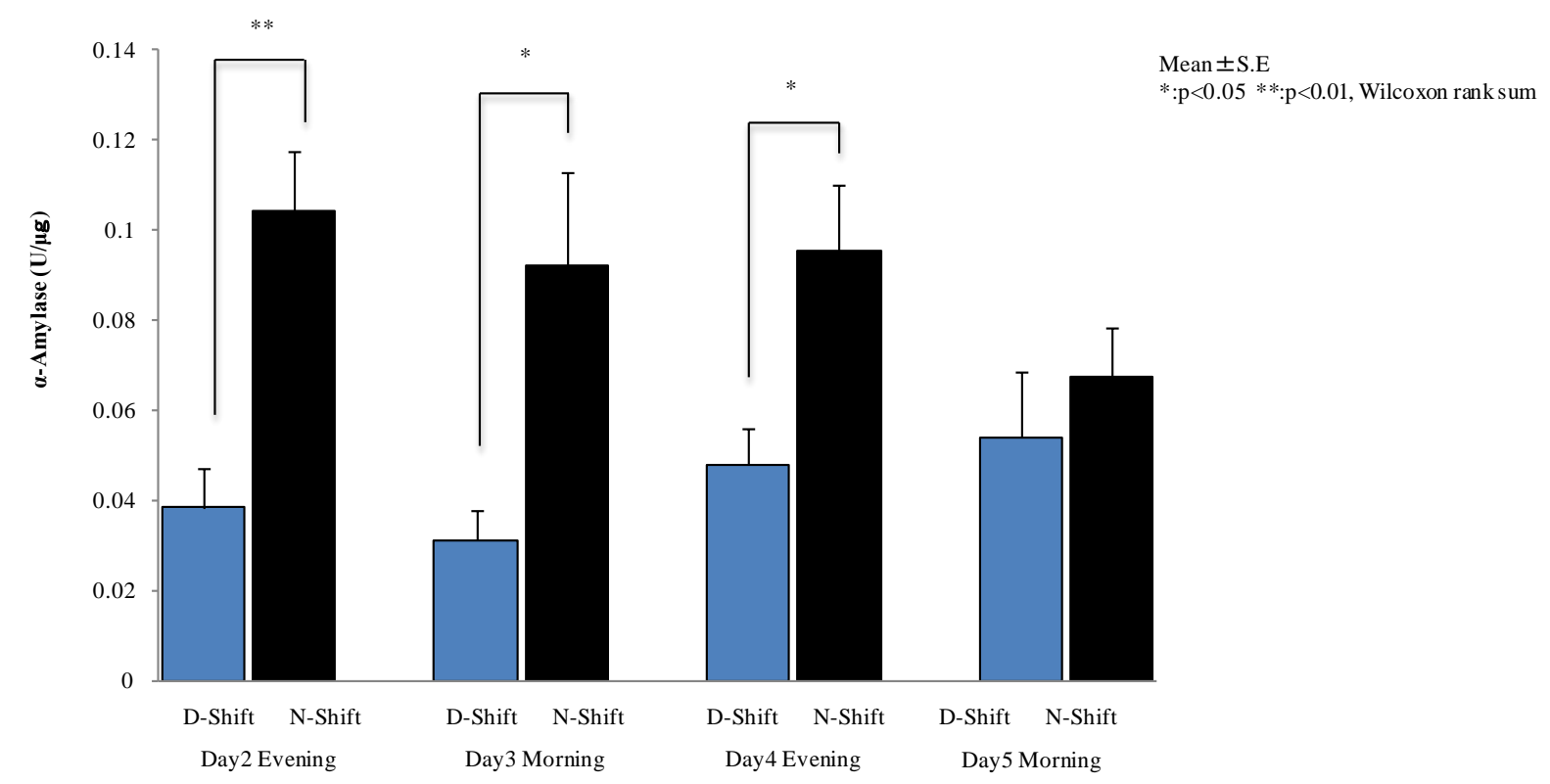

Figure 9. Comparative analysis between day and night shift nurses (Wilcoxon rank sum test).

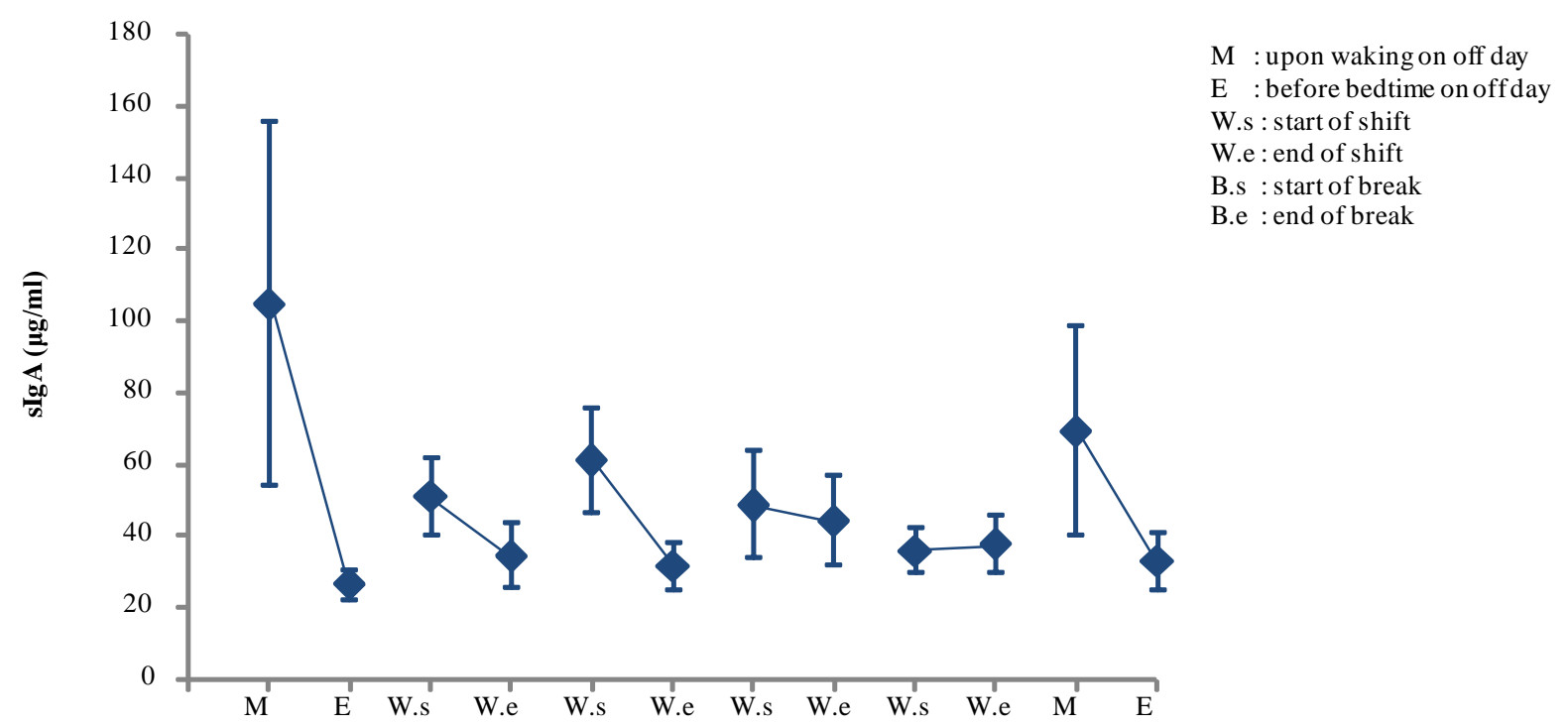

Figure 10. Changes in salivary sIgA levels of day shift work (mean \pm S.E.).

Among the nighttime nurses, high levels of sIgA $(91.250 \pm 31.204 \mu \mathrm{g} / \mathrm{mL})$ were observed on the morning of a non-working day (day 1 ), which declined thereafter. The highest sIgA levels actually occurred after the break on the first of the 4 day shift (day 2) $(98.133 \pm 22.804 \mu \mathrm{g} / \mathrm{mL})$, ending the shift with an overall high average sIgA levels $(69.323 \pm 31.589 \mu \mathrm{g} / \mathrm{mL})$. On the other hand, day 3 kicked off with low sIgA levels $(34.296 \pm 14.162$ $\mu \mathrm{g} / \mathrm{mL}$ ) and no other marked changes were observed until the end of that shift. On the morning of the off day at the end of the study period (day 6), sIgA levels rose again $(84.68 \pm 29.881 \mu \mathrm{g} / \mathrm{mL}$ ), only to decline before bedtime $(20.455 \pm 5.271 \mu \mathrm{g} / \mathrm{mL})$ (see Figure 11$)$.

There were no significant differences between day and night shift nurses (see Figure 12).

\section{Discussion}

In this study, cortisol levels among day shift nurses showed normal circadian rhythm despite work stress; however, night workers demonstrated apparent disruption in the circadian pattern. Our results indicate that $16 \mathrm{~h}$ 


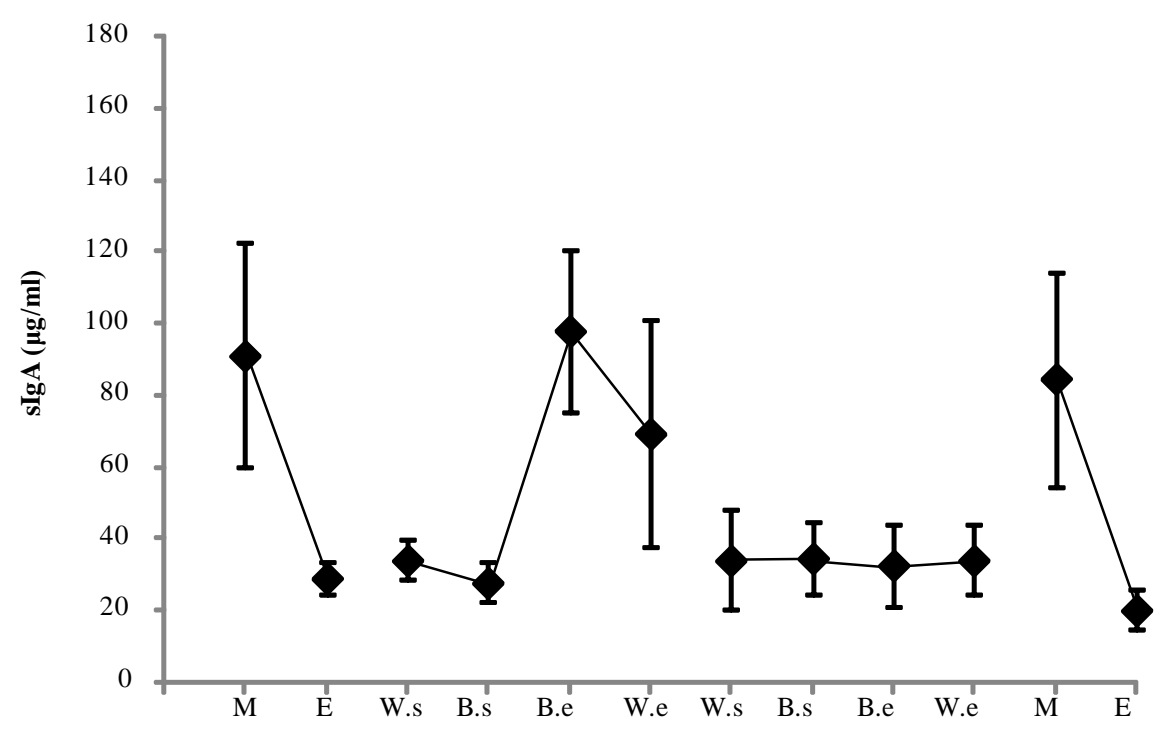

M : upon waking on off day E : before bedtime on off day W.s : start of shift W.e : end of shift B.s : start of break B.e : end of break

Figure 11. Changes in salivary sIgA levels of night shift work (mean \pm S.E.).

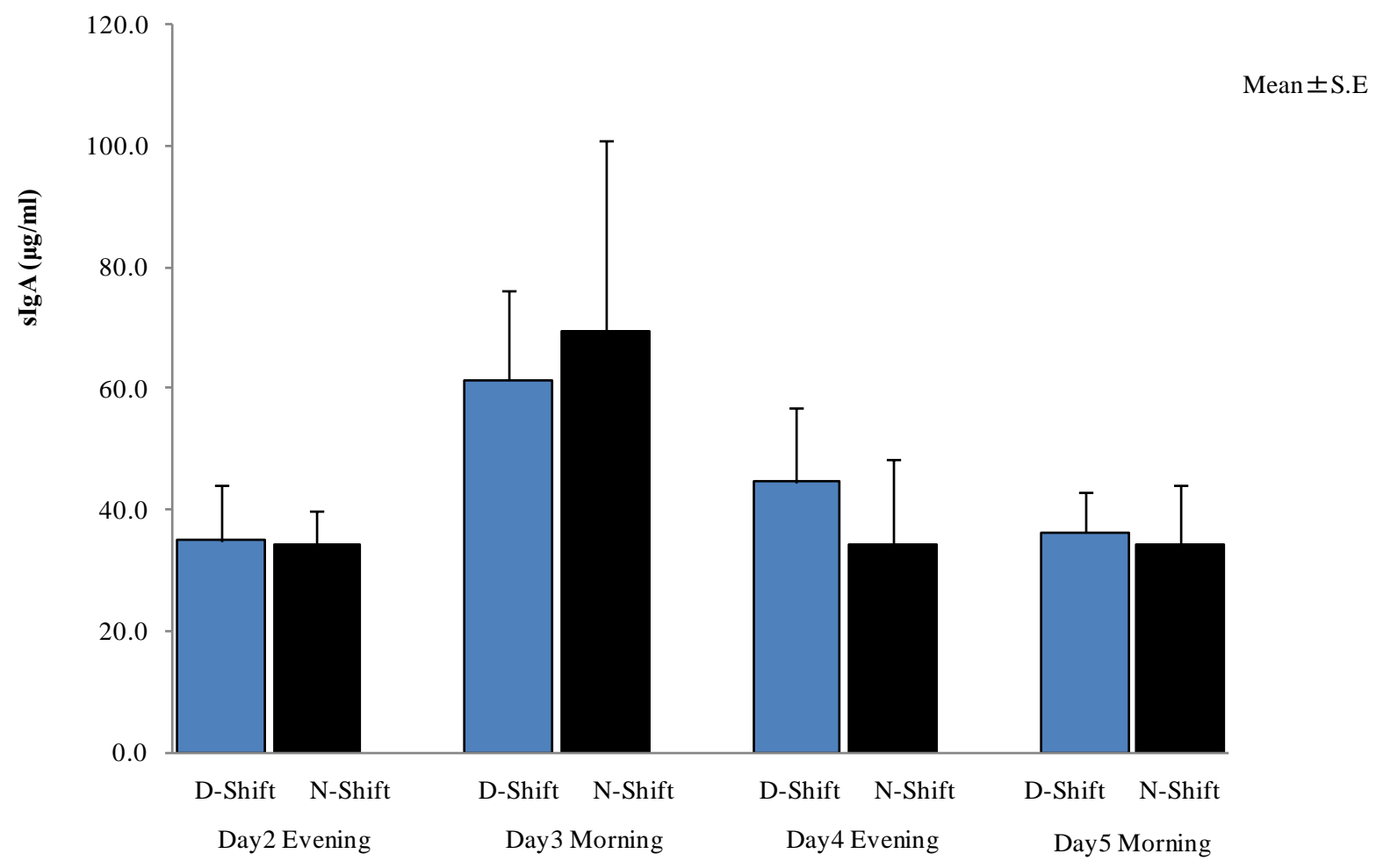

Figure 12. Comparative analysis between day and night shift nurses (Wilcoxon rank sum test).

night shift work demonstrated marked circadian misalignment.

Cortisol secretion is known to show a distinct diurnal pattern with the highest level in the morning and lowest at night [5] [8]. Shift workers, particularly night workers, are reported to suffer impaired circadian rhythm of cortisol release [9]. In this study, cortisol levels of day shift nurses showed normal diurnal fluctuations, but the kinetic changes observed among night shift nurses indicated that their bodies adjusted to the start of the night shift as if they were operating in the morning.

In the evening on the first and third working days, cortisol levels of night shift nurses were significantly higher than those of the day shift nurses, and in the morning on the second working day, cortisol levels of night shift 
nurses were significantly lower than that of the day shift nurses.

Our findings showed that salivary components indeed reflect the biochemical mechanisms of impaired circadian rhythm induced by a $16 \mathrm{~h}$ night shift. Underpinning our findings are studies that demonstrate similar circadian variation in cortisol levels and other salivary biomarkers such as $\alpha$-amylase activity, sIgA levels, and chromogranin A levels that show morning spikes and evening lows [10]-[15].

The shift system is an irregular and random mixture of day and night shifts interspersed with sporadic off days. Under normal conditions, the human body prepares for the day by manufacturing just enough stress hormones upon rising in accord with the natural circadian rhythm [1].

Day shift nurses tend to show a normal circadian pattern of stress hormones that are high in the morning and low at night, while night shift nurses tend to follow a pattern in which the start of the shift corresponds with an "active morning mode", most likely due to the short nap taken before the shift. Thereafter, the stress hormones mimic the "end of the day" mode of a normal diurnal rhythm during break, recovering to the "active morning mode" after the break, and finally leveling off for the "night” mode at the end of the night shift, i.e., early morning.

When the body is under stress, two principal components of stress response become activated: the sympathoadrenomedullary system and the hypothalamic-pituitary-adrenal cortex axis (HPA axis). These systems release catecholamines and cortisol, respectively, to prepare the body to handle stress by increasing heart rate and mobilizing blood glucose for energy. Cortisol is a hormone released by the HPA system and is considered one of the classic endogenous markers of stress [16]. In addition, cortisol levels measured in the blood and saliva [17] are reported to be highly congruent [18].

Chromogranin A is a hormone produced by the sympathoadrenomedullary system and found in the submandibular duct, an area involved in the storage of catecholamines, and released during sympathetic activation [19]. Chromogranin A is increasingly garnering attention as a stress marker reflecting sympathetic dominance and touted as useful for monitoring psychological stress [19]. It is reported to elevate in times of acute stress such as test taking [20].

In this study, both day and night shift nurses had normal diurnal variations of chromogranin A levels on non-working days. Among night workers, day 2 was marked by mild elevations occurring shortly before the break until the end of shift, while on day 3 , the levels increased significantly from the start of shift until the break. These findings are thought to correspond with the busiest times during the night shift, i.e., time until patients' bedtime and the early morning hours when the patients wake up and shift change occurs [1]. Interestingly, our results of $\alpha$-amylase activity did not show clear signs of physical stress. The activity of $\alpha$-amylase has been used in numerous studies as a marker of physical and psychological stress and is reported to increase during physical stress [21], with high activity as a correlate for physical fatigue. However, throughout each period, the $\alpha$-amylase activity of the night shift nurses was consistently and significantly higher than that of the day shift nurses, thus we surmised that night shift nurses are placed under conditions of greater stress than those of day shift nurses. The fluctuations in chromogranin A levels among night shift workers suggested that in spite of the inherent psychological stress of the nocturnal schedule, physical stress relative to psychological stress was not as prominent. This indicates that chromogranin A levels may not have been affected by the nurses' activity levels during the shift on any given day; nevertheless, activity levels should be accounted for in future evaluations. Furthermore, an additional investigation of the one nurse with significant increase in both chromogranin A and $\alpha$-amylase activity levels are needed to determine the cause of the marked elevations during the study period.

According to our results of the sIgA levels, changes in physical stress levels were relatively minimal before and after daytime shifts, which contrasted sharply with the significant changes observed before and after the night shifts, rendering it difficult for us to draw a definitive conclusion about the implications of sIgA levels from our results alone.

The sIgA level is known to fluctuate in response to physical stress and has been used as a stress marker in many studies, but the results have been inconsistent at best. For example, university students undergoing exams [22] and prisoners [23] have been shown to have decreased levels; similarly, emergency nurses working under high stress conditions have been reported to have low sIgA levels [2]. The sIgA level is also known to decrease in a similar manner in people with a pessimistic outlook on life [24], thus studies are consistent in terms of chronic stress inducing decreased sIgA levels. By contrast, sIgA levels in soccer coaches during a competition [22] and in air traffic controllers while on duty [25] are known to increase before and after the competition or duty, respectively. Furthermore, subjects under acute stress such as performing mental arithmetic or undergoing 
a cold pressor test are known to have increased sIgA levels [26]-[28]. Yet interestingly enough, other studies have reported contradictory findings during times of acute stress [29] [30].

The activity levels of night shift nurses appear to peak during specific times of concentrated busyness, including the time until patients' bedtime, meal times, and early morning hours when the patients arise and shift change occurs [1]. In addition, nurses in the mental ward relative to those in other wards are known to be subjected to high levels of psychological stress associated with the caring of psychiatric patients [5]. On the basis of these findings, the psychiatric ward of Juntendo University Koshigaya Hospital conjectured that several factors may affect the activity levels during a night shift, including the trepidation towards a two-people night shift system and concern about the ability to cope with acute exacerbations in patients. For these reasons, it may be prudent to simultaneously study the effects of spontaneous events that arise during the shift and the nature of relationships among team members in addition to an evaluation of physiological changes.

Salivary testing has captured widespread attention as a non-invasive and convenient biochemical analysis of fatigue and stress [6] [7]. The analysis of salivary components to objectively measure stress levels indicates its potential use in improving work hours and monitoring health among nurses. In the future, salivary component analysis performed in conjunction with conventional psychological tests and questionnaires to determine the levels of fatigue and stress among nurses may help generate objective and highly reliable, informative data. One question still unanswered is whether there are differences between men and women given that stress reaction and physical fatigue may be different. Further studies would benefit from taking sex differences into consideration.

Although this study followed the nurses over a short term of four consecutive workdays, our results demonstrated marked circadian misalignment in salivary cortisol and $\alpha$-amylase activity levels among nurses on $16 \mathrm{~h}$ night shifts. Thus, our data imply that a restructuring of the shift system to mimic the circadian rhythm may help minimize disruptions and lead to greater prevention of stress and fatigue.

\section{Acknowledgements}

The authors would like to thank the nurses at the Juntendo Koshigaya hospital, School of Medicine, Juntendo University, for their participation in this study.

\section{References}

[1] Oriyama, S., Miyakoshi, Y., et al. (2011) Influence of Night-Shift Work on Nurses. Journal of the Japan Society for Healthcare Administration, 48, 147-156.

[2] Yang, Y., Koh, D., Ng, V., Lee, C.Y., Chang, G., Dong, F., Goh, S.H., Anantharaman, V. and Chia, S.E. (2002) Self Perceived Work Related Stress and the Relation with Salivary IgA and Lysozyme among Emergency Department Nurses. Occupational and Environmental Medicine, 59, 836-841. http://dx.doi.org/10.1136/oem.59.12.836

[3] Fujimaru, C., Okamura, H., Kawasaki, M., Kakuma, T., Yoshii, C. and Matsuishi, T. (2012) Self-Perceived Work-Related Stress and Its Relation to Salivary IgA, Cortisol and 3-Methoxy-4-Hydroxyphenyl Glycol Levels among Neonatal Intensive Care Nurses. Stress Health, 28, 171-174. http://dx.doi.org/10.1002/smi.1414

[4] Sato, K. and Amano, A. (2000) Investigation of Relation between Working Conditions and Accumulative Fatigue in Nurses. Journal of Oita Nursing and Health Sciences, 2, 1-7.

[5] Motomura, Y. and Yatsushiro, R. (2010) Factors Relating to Nurse Burnout. Japanese Society of Occupational Medicine and Traumatology, 58, 120-127.

[6] Soo-Quee Koh, D. and Choon-Huat Koh, G. (2007) The Use of Salivary Biomarkers in Occupational and Environmental Medicine. Occupational and Environmental Medicine, 64, 202-210. http://dx.doi.org/10.1136/oem.2006.026567

[7] Izawa, S., Shirotsuki, K., Sugaya, N., Ogawa, N., Suzuki, K. and Nomura, S. (2007) The Application of Saliva to an Assessment of Stress: Procedures for Collecting and Analyzing Saliva and Characteristics of Salivary Substances. Japanese Journal of Complementary and Alternative Medicine, 4, 91-101. http://dx.doi.org/10.1625/jcam.4.91

[8] Miyauchi, F., Kimura, K., et al. (2012) Effects of Working at Night on Plasma Cortisol Concentrations and BMI in Female Nurses. Japanese Society of Occupational Medicine and Traumatology, 60, 348-352.

[9] Harris, A., Waage, S., Ursin, H., Hansen, A.M., Bjorvatn, B. and Eriksen, H.R. (2010) Cortisol, Reaction Time Test and Health among Offshore Shift Workers. Psychoneuroendocrinology, 35, 1339-1347. http://dx.doi.org/10.1016/j.psyneuen.2010.03.006

[10] Pruesser, J.C., Wolf, O.T., Hellhammer, D.H., Buske-Kirschbaum, A., von Auer, K., Jobst, S., Kaspers, F. and Kir- 
schbaum, C. (1997) Free Cortisol Levels after Awakening: A Reliable Biological Marker for the Assessment of Adrenocortical Activity. Life Sciences, 61, 2539-2549. http://dx.doi.org/10.1016/S0024-3205(97)01008-4

[11] Clow, A., Thorn, L., Evans, P. and Hucklebridge, F. (2004) The Awakening Cortisol Response: Methodological Issues and Significance. Stress, 7, 29-37. http://dx.doi.org/10.1080/10253890410001667205

[12] Hucklebridge, F., Clow, A. and Evans, P. (1998) The Relationship between Salivary Secretory Immunoglobulin A and Cortisol: Neuroendocrine Response to Awakening and the Diurnal Cycle. International Journal of Psychophysiology, 31, 69-76. http://dx.doi.org/10.1016/S0167-8760(98)00042-7

[13] Nater, U.M., Rohlder, N., Schlotz, W., Ehlert, U. and Kirschbaum, C. (2007) Determinants of the Diurnal Course of Salivary Alpha-Amylase. Psychoneuroendocrinology, 32, 392-401. http://dx.doi.org/10.1016/j.psyneuen.2007.02.007

[14] Den, R., Toda, M., Nagasawa, S., Kitamura, K. and Morimoto, K. (2007) Circadian Rhythm of Human Salivary Chromogranin A. Biomedical Research, 28, 57-60. http://dx.doi.org/10.2220/biomedres.28.57

[15] Shirakawa, T., Mitome, M. and Oguchi, H. (2004) Circadian Rhythms of S-IgA and Cortisol in Whole Saliva-Compensatory Mechanism of Oral Immune System for Nocturnal Fall of Saliva Secretion. Pediatric Dental Journal, 14, 115-120. http://dx.doi.org/10.1016/S0917-2394(04)70017-8

[16] Ohira, T., Okada, M. and Shimamoto, T. (2004) Effects of Foot Baths on Peripheral Skin Temperature, Blood Flow, and Salivary Cortisol. Biomedical Thermology, 23, 181-185.

[17] Kahn, J.P., Rubinow, D.R., Davis, C.L., Kling, M. and Post, R.M. (1988) Salivary Cortisol: A Practical Method for Evaluation of Adrenal Function. Biological Psychiatry, 23, 335-349. http://dx.doi.org/10.1016/0006-3223(88)90284-3

[18] Hellhammer, D.H., Wüst, S. and Kudielka, B.M. (2009) Salivary Cortisol as a Biomarker in Stress Research. Psychoneuroendocrinology, 34, 163-171. http://dx.doi.org/10.1016/j.psyneuen.2008.10.026

[19] Tsunoda, T. (2008) Salivary Chromogranin A as Index of Psychosomatic Stress Response. The Journal of Meikai Dental Medicine, 37, 42-49.

[20] Takatsuji, K., Sugimoto, Y., Ishizaki, S., Ozaki, Y., Matsuyama, E. and Yamaguchi, Y. (2008) The Effects of Examination Stress on Salivary Cortisol, Immunoglobulin A, and Chromogranin A in Nursing Students. Biomedical Research, 29, 221-224. http://dx.doi.org/10.2220/biomedres.29.221

[21] Li, T.L. and Gleeson, M. (2004) The Effect of Signal and Repeated Bouts of Prolonged Cycling and Circadian Variation on Saliva Flow Rate, Immunoglobulin A and Alpha-Amylase Response. Journal of Sports Sciences, 22, 10151024. http://dx.doi.org/10.1080/02640410410001716733

[22] Jemmott, J.B., Borysenko, J.Z., Borysenko, M., McClelland, D.C., Chapman, R., Meyer, D. and Benson, H. (1983) Academic Stress, Power Motivation, and Decrease in Salivary Immunoglobulin A Secretion Rate. Lancet, 321, 14001402. http://dx.doi.org/10.1016/S0140-6736(83)92354-1

[23] McClelland, D.C., Alexander, C. and Marks, E. (1982) The Need for Power, Stress, Immune Function and Illness among Male Prisoners. Journal of Abnormal Psychology, 91, 61-70. http://dx.doi.org/10.1037/0021-843X.91.1.61

[24] Evans, P., Bristow, M., Hucklebridge, F., Clow, A. and Walters, N. (1993) The Relationship between Secretory Immunity: Mood and Life Events. British Journal of Clinical Psychology, 32, 227-236. http://dx.doi.org/10.1111/j.2044-8260.1993.tb01050.x

[25] Zeier, H., Brauchli, P. and Joller-Jemelka, H.I. (1996) Effects of Work Demands on Immunoglobulin A and Cortisol in Air Traffic Controllers. Biological Psychology, 42, 413-423. http://dx.doi.org/10.1016/0301-0511(95)05170-8

[26] Bristow, M., Hucklebridge, F., Clow, A., Evans, P. and Philip, D. (1997) Modulation of Secretory Immunoglobulin A in Saliva in Relation to an Acute Episode of Stress and Arousal. Journal of Psychophysiology, 11, 248-255.

[27] Carroll, D., Ring, C., Shrimpton, J., Evans, P., Willemsen, G. and Hucklebridge, F. (1996) Secretory Immunoglobulin A and Cardiovascular Responses to Acute Psychological Challenge. International Journal of Behavioral Medicine, 3, 266-279. http://dx.doi.org/10.1207/s15327558ijbm0303_6

[28] Willemsen, G., Ring, C., Carroll, D., Evans, P., Clow, A. and Hucklebridge, F. (1998) Secretory Immunoglobulin A and Cardiovascular Reactions to Mental Arithmetic and Cold Pressor. Psychophysiology, 35, 252-259. http://dx.doi.org/10.1111/1469-8986.3530252

[29] Kugler, J., Reintjes, F., Tewes, V. and Schedlowski, M. (1996) Competition Stress in Soccer Coaches Increased Salivary Immunoglobulin A and Salivary Cortisol Concentration. Journal of Sports Medicine and Physical Fitness, 36, 117-120.

[30] Ring, C., Harrison, L.K., Winzer, A., Carroll, D., Drayson, M. and Kendall, M. (2000) Secretory Immunoglobulin A and Cardiovascular Reactions to Mental Arithmetic, Cold Pressor, and Exercise: Effects of Alpha-Adrenergic Blockade. Psychophysiology, 37, 634-643. http://dx.doi.org/10.1111/1469-8986.3750634 
Scientific Research Publishing (SCIRP) is one of the largest Open Access journal publishers. It is currently publishing more than 200 open access, online, peer-reviewed journals covering a wide range of academic disciplines. SCIRP serves the worldwide academic communities and contributes to the progress and application of science with its publication.

Other selected journals from SCIRP are listed as below. Submit your manuscript to us via either submit@scirp.org or Online Submission Portal.
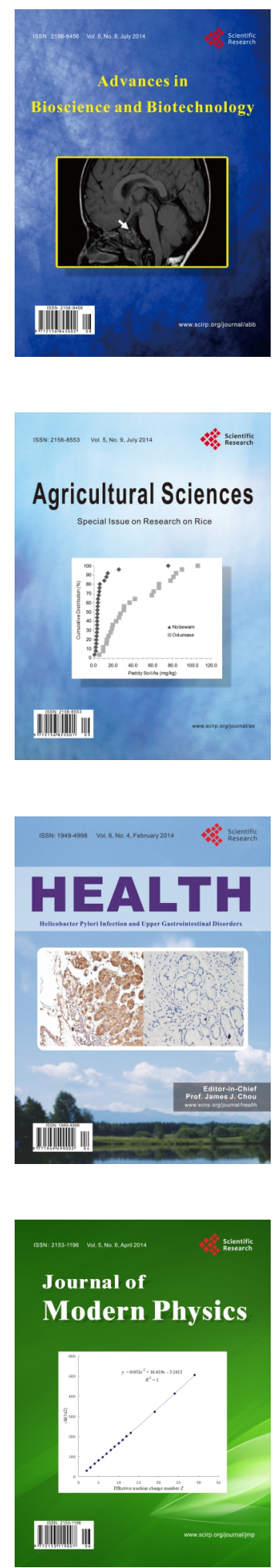
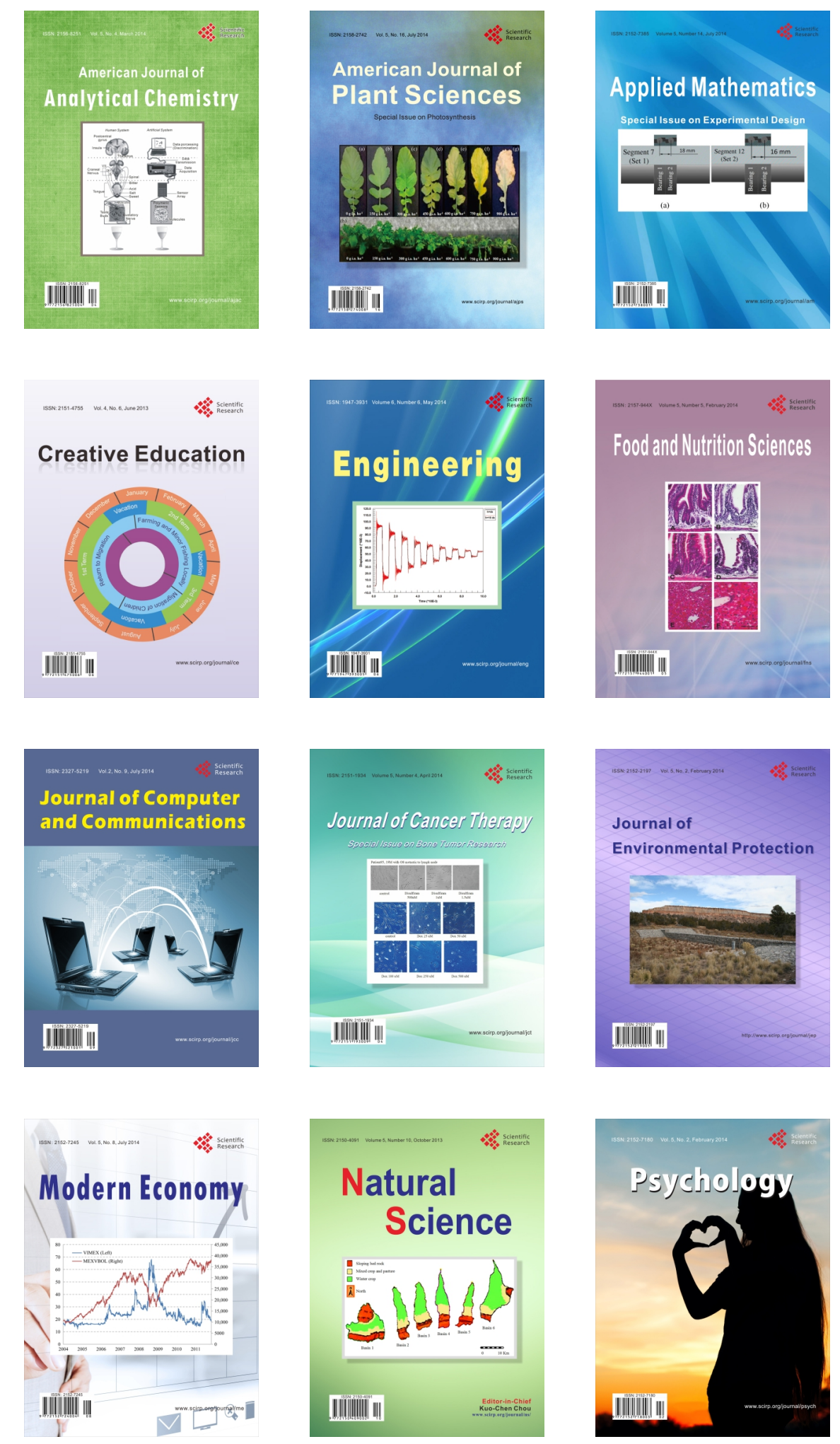